\title{
PRIKAZ PACIJENTA SA GOJAZNOŠĆU TREĆEG STEPENA, METABOLIČKIM SINDROMOM, POVEĆANIM KARDIOVASKULARNIM RIZIKOM I ELEKTROLITNIM DISBALANSOM TOKOM TRETMANA REDUKCIJE TELESNE TEŽINE U SPECIJALNOJ BOLNICI ČIGOTA
}

\begin{abstract}
Sažetak: Program Čigota je medicinski program namenjen za redukciju telesne težine. Koncepcija programa je zasnovana na: dobro izbalansiranoj dijeti, strogo određenoj i doziranoj fizičkoj aktivnosti i edukativnim predavanjima. Pacijent, životne dobi 27 godina, hospitalizovan u Specijalnoj bolnici Čigota u okviru Čigota programa. U 19. godini života počeo da dobija na težini, a unazad 2 godine se ugojio, oko $110 \mathrm{~kg}$. Leči se od psihoze (shizophrenia). Do dana prijema u našu ustanovu nije hospitalno lečena gojaznost. Antropometrijske mere na dan prijema BMI: $64,58 \mathrm{~kg} / \mathrm{m}^{2}$, telesne masti: $47.8 \%(110,8 \mathrm{~kg})$, obim struka: $180 \mathrm{~cm}$. Objektivnim pregledom utvrđena gojaznost trećeg stepena, metabolički sindrom i hipertenzija prvog stepena. Pacijent je uz 24h medicinski nadzor podvrgnut dijetetskom režimu ishrane, doziranoj fizičkoj aktivnosti, fizikalnom tretmanu i svakodnevnoj psihološkoj obradi. U okviru tretmana gojaznosti došlo je do razvoja elektrolitnog disbalansa koji je protumačen kao diluciona hiponatremija sa hipokalijemijom, umerene simptomatologije i hroničnog razvoja i korigovan je tokom narednih sedam dana adekvatnom peroralnom suplementacijom kalijuma, natrijuma, magnezijuma i restrikcijom unosa tečnosti. Na kraju tretmana (160 dana) postignut je ukupan gubitak telesne mase od 105,8 kg, odnosno za $45,86 \%$ prvobitne težine. Postignuta je značajna redukcija telesnih masti za $68,8 \%$ prvobitnih vrednosti, redukcija obima struka za $61 \mathrm{~cm}$, odnosno 33,8\%. Uspostavljena nefarmakološka regulacija hipertenzije, regulacija glikemije i triglicerida, uspostavljen povoljan profil frakcija holesterola (HDL/LDL), značajno redukovana vrednost mokraćne kiseline u serumu. I nakon dve godine od započinjanja tretmana gojaznosti u našoj ustanovi pacijent je u kućnim uslovima nastavio trend gubitka telesne mase i postigao prelazak iz kategorije gojazan u kategoriju pre-
\end{abstract}

\footnotetext{
Aleksandar Đenić, Specijalna bolnica za bolesti štitaste žlezde i bolesti metabolizma Zlatibor, djenic.cigota@gmail.com
} 
komerno uhranjen, uspostavljena je stabilna regulacija krvnog pritiska i popravljeni metabolički parametri kardiovaskularnog rizika (glikemija, holesterol sa frakcijama, trigliceridi, mokraćna kiselina), a u nalazu ultrazvuka srca došlo je do redukcije debljine septuma i popravljanja ejekcione frakcije srca.

Ključne reči: gojaznost, kardiovaskularni rizik, elektrolitni disbalans, gubitak težine.

Prekomerna uhranjenost i gojaznost su faktori rizika za razvoj kardiovaskularnih oboljenja, insulta, dijabetesa, karcinoma, a posebno hipertenzije koja je udružena sa kardiorenalnim i metaboličkim oboljenjima i povećanim mortalitetom. (1)

Mortalitet zbog gojaznosti raste za $30 \%$ za svako povećanje BMI za 5 jedinica. (1) Posebnu ulogu ima povećana visceralna mast (abdominalna gojaznost) koja predstavlja izvor citokina i drugih faktora inflamacije i oksidativnog stresa koji doprinose razvoju endotelne disfunkcije, ateroskleroze i insulinske rezistencije. (2)

Gubitak težine i svakodnevna umerena fizička aktivnost dovode do smanjenja mase i debljine zida LK, smanjenja krutosti arterija, poboljšanja endotelne disfunkcije, što dovodi do smanjenja krvnog pritiska i kardiometaboličkog rizika i povećanja osetljivosti ciljnih tkiva na insulin. (3)

Program Čigota je medicinski program namenjen za redukciju telesne težine i promenu životnog stila. Koncepcija Čigota programa je zasnovana na dobro izbalansiranoj dijeti, strogo određenoj i doziranoj fizičkoj aktivnosti, edukativnim predavanjima i motivaciono-emocionalnom aspektu prema pojedincu (korisniku programa). Suština programa je u uspostavljanju poremećene ravnoteže između unosa energije i potrošnje, smanjenje telesne težine i redukovanje faktora kardiometaboličkog rizika, održavanje postignutog gubitka telesne težine, prevencija gojaznosti i poboljšanje fizičkih sposobnosti bez obzira na godine, starost i pol.

Prosečan gubitak kilograma za dve nedelje boravka na programu je $5,8 \mathrm{~kg}$, pri čemu prosečno 5,4 kg gube žene, a 6,2 kg muškarci. Dijete se individualno propisuju, a sve su hipokalorijske sa očuvanom nutritivnom vrednošću namirnica i uravnoteženim odnosom hranljivih materija. Dnevni energetski unos kreće se prosečno između 1000 i $1500 \mathrm{kcal}$. Unos soli je redukovan na maksimalno $3 \mathrm{~g}$ dnevno. Fizičke aktivnosti su strogo dozirane, sprovode se 3-4 sata dnevno i obuhvataju duge, rekreativne šetnje, vežbe u sali i vežbe u bazenu.

\section{Prikaz slučaja:}

Pacijent B. I. 27 godina, hospitalizovan u Specijalnoj bolnici Čigota u okviru Čigota programa. Tokom prijema u ustanovu navodi tegobe: gušenje, zamaranje, otoke nogu i ruku, ne može da spava u ležećem položaju - samo u polusedećem (san je isprekidan - budi se na svakih pola sata), ima ubrzaniji puls, zamaranje nakon par 
metara hoda po ravnom. Leči se unazad 5 godina od psihoze (shizophrenia), a od terapije uzima Leponex tbl. 100mg, 2 tbl. uveče. Često ima prisutan osećaj nervoze, napetosti i strahova.

Istorija gojaznosti: na kraju gimnazije, u 19. godini života počeo da dobija na težini. Tada je imao oko $100 \mathrm{~kg}$. Intenzivno je trenirao borilački sport. U naredne 2 godine održavao težinu oko $100-110 \mathrm{~kg}$. Od 22. godine počeo da konzumira alkohol i narkotike (kokain). Prestao je da se bavi sportom. U tom periodu počeo intenzivno da dobija na težini - ugojio se oko $40 \mathrm{~kg}$ i tada je imao oko $160 \mathrm{~kg}$ (u 24. godini). Sprovodio dijetetski režim ishrane po savetu lekara i nutricioniste i izgubio oko 40 $\mathrm{kg}$. Od 25. godine ponovo rapidno dobija na težini (uz kratkotrajno sprovođenja dijetetskog režima ishrane od kojih je brzo odustajao) i tokom naredne 2 godine se ugojio još oko $110 \mathrm{~kg}$. U međuvremenu, kako navodi, prestao je da uzima narkotike i alkohol. Redovno uzima propisane lekove - antipsihotike. Do dana prijema u našu ustanovu nije hospitalno lečena gojaznost.

Antropometrijske mere na dan prijema: TV: $189 \mathrm{~cm}$, TM: 230,7 kg, BMI: 64,58 $\mathrm{kg} / \mathrm{m}^{2}$, telesne masti: $47.8 \%$ (110,8 $\mathrm{kg}$ ), obim struka: $180 \mathrm{~cm}$. U biohemijskim analizama krvi prisutan zapaljenski sindrom: povišena sedimentacija eritrocita SE-38 i CRP-34. Registrovane povišene vrednosti glikemije (6.6mmol/L, HbA1c: 5.9\%). U lipidnom statusu povišeni trigliceridi i poremećen odnos HDL/LDL, što ukazuje na povećan kardiovaskularni rizik: holesterol - $4.51 \mathrm{mmol} / 1$ (HDL- $0,8 \mathrm{mmol} / 1$, LDL-3,4 $\mathrm{mmol} / \mathrm{l})$, trigliceridi $-4.35 \mathrm{mmol} / \mathrm{l}$. Proteini u serumu i azotne materije u referentnim vrednostima. Registrovane su izrazito povišene vrednosti urata: mokraćna kiselina $-1137 \mathrm{mikromol} / \mathrm{l}$ (normalno manje od $430 \mathrm{mikromol} / \mathrm{L}$ ). Vrednosti elektrolita su u referentnim vrednostima $(\mathrm{Na}-139 \mathrm{mmol} / \mathrm{l}, \mathrm{K}-4.2 \mathrm{mmol} / \mathrm{l}, \mathrm{Cl}-110 \mathrm{mmol} / \mathrm{l}, \mathrm{Ca}$ $-2.47 \mathrm{mmol} / \mathrm{l})$. Tireoidni funkcionalni status je uredan (FT4 - 15.3, TSH - 3.63).

Objektivnim pregledom registrovana hipertenzija prvog stepena (TA: $150 / 85 \mathrm{~mm}$ $\mathrm{Hg}$ leva ruka , 155/90 mm $\mathrm{Hg}$ desna ruka). U EKG-u registrovan sinusni ritam, ST depresija od $0.5 \mathrm{~mm}$ u inferiornim odvodima, negativan T u D3. Auskultatorno nad plućima produžen ekspirijum, pooštren disajni šum, uz niskotonski vizing. Akcija srca ritmična, tonovi mukli, bez šumova sa tahikardijom u miru 110/ min. Prisutni izraziti testasti edemi nogu i ruku. Na ultrazvuku srca registrovane granične dimenzije leve komore $(57 / 39 \mathrm{~mm})$, zadebljali septum (IVS: $11 \mathrm{~mm}$ ). Globalno je registrovana dobra kontraktilnost leve komore, bez ispada segmentne kinetike sa EF: 62\%. Prisutna i lako uvećana leva pretkomora $(41 \mathrm{~mm})$ i blagi stepen trikupidalne regurgitacije (TR: 1+, SPDK: $22 \mathrm{~mm} \mathrm{Hg}$ ) i raslojen perikard iza zadnjeg zida. Opisani nalazi odgovaraju gojaznosti trećeg stepena (maligna gojaznost), metaboličkom sindromu i hipertenziji prvog stepena.

U Specijalnoj bolnici Čigota pacijent je, uz 24h medicinski nadzor, podvrgnut dijetetskom režimu ishrane, doziranoj fizičkoj aktivnosti, fizikalnom tretmanu, svakodnevnoj psihološkoj obradi i uz konsultaciju psihijatra nastavio da uzima ranije ordini- 
ranu dozu antipsihotika, uz dodatak anksiolitika (Rivotril, $2 \mathrm{mg} 3 \times 1 / 2$ tbl). Redovna kontrola elektrolita i biohemijskih analiza krvi sprovođena svakih 7 dana tretmana.

Tokom prvih nedelja inicijalno počeo da gubi oko $4 \mathrm{~kg}$ nedeljno, da bi od desete nedelje gubitak težine bio sporiji - oko $2-3 \mathrm{~kg}$ nedeljno. Tenzija je od druge nedelje boravka bila u referentnim vrednostima: vrednosti od 128-136/ 82-88 mm Hg. Vrednosti jutarnje glikemije su bile 5.6-6.2 mmol/1. Povlačenje otoka nogu i ruku registrovano je već krajem prve nedelje, a od treće nedelje prisutni samo diskretni predtibijalni edemi. Intenzivnija diureza do $4.51 / 24 \mathrm{~h}$ prve dve nedelje, potom između 2.5-31/24h. Od četvrte nedelje boravka mogao je da hoda po ravnom $1.5 \mathrm{~km}$ bez zamora. Nakon šest nedelja san je postao kontinuiran, više nije imao gušenja, počeo da spava na ravnijem uzglavlju. U toku devete nedelje boravka dolazi do pojave izražene opstipacije uz meteorizam, koja je nakon par dana regulisana primenom više različitih laksativa i klizmama. Od tada, do kraja hospitalizacije stolica je bila uredna.

Tokom 89. dana tretmana gojaznosti dolazi do pojave izraženog zamora, malaksalosti, glavobolje, mučnine i grčeva u mišićima. U laboratorijskim analizama registrovan pad elektrolita: hiponatrijemija, hipokalijemija i hipohloremija $(\mathrm{Na}-122$ $\mathrm{mmol} / \mathrm{l}, \mathrm{K}-2.3 \mathrm{mmol} / \mathrm{l}, \mathrm{Cl}-77 \mathrm{mmol} / \mathrm{L}$ ). Azotne materije u krvi bile u referentnim vrednostima. Registrovan i pad krvnog pritiska: TA: 105/65 mm Hg uz normalan puls (frekvenca $84 / \mathrm{min}$ ). U EKG-u nisu registrovane promene ST segmenta i T talasa koje bi ukazivale na registrovane elektrolitne poremećaje (bez dinamike promena slike EKG-a u odnosu na dan prijema). Anamnestički se saznaje da unosi veću količinu vode (6-7 litara/dan) zbog vrućine i prekomernog znojenja i svakodnevnog vežbanja, a poznata je činjenica prekomernog unosa tečnosti koji se često registruje kod pacijenta koji imaju dijagnozu psihoze.

Navedeni pad elektrolita protumačen je kao diluciona hiponatrijemija sa niskim nivoom kalijuma. Savetovana je redukcija unosa tečnosti, unos $3 \mathrm{~g} \mathrm{KCl}$ prva tri dana, a potom $2 \mathrm{~g} \mathrm{KCl} /$ dnevno per os i dodatak soli ishrani, unos magnezijuma $(375 \mathrm{mg}$ per os), kao i prekid vežbanja. Nakon trećeg dana terapije uspostavljena je korekcija elektrolita u serumu i na sledećem merenju: $\mathrm{Na}-139 \mathrm{mmol} / \mathrm{l}, \mathrm{K}-3.2 \mathrm{mmol} / \mathrm{l}, \mathrm{Cl}$ - $98 \mathrm{mmol} / \mathrm{l}$. Pacijent se bolje osećao, bez grčeva u mišićima uz samo blaži osećaj malaksalosti i mučnine. Nakon sedmog dana opisanog tretmana upostavljena je potpuna korekcija nastalog elektrolitnog disbalansa $(\mathrm{Na}-138 \mathrm{mmol} / \mathrm{l}, \mathrm{K}-3.9 \mathrm{mmol} / \mathrm{l}$, $\mathrm{Cl}-102 \mathrm{mmol} / \mathrm{l}$ ) uz kompletno povlačenje tegoba. Sva sledeća merenja elektrolita tokom boravka bila su u referentnim vrednostima.

Nastavljena je dijeta i dozirana fizička aktivnost. Vrednosti tenzije su bile u referentnim vrednostima (od 115-128/75-84 mm Hg). Nastavljen je gubitak težine, prosečno 2-3 kg nedeljno.

Antropometrijska merenja na otpustu, nakon 160 dana tretmana gojaznosti TV: $189 \mathrm{~cm}$, TM: $125,9 \mathrm{~kg}$, BMI: $35,25 \mathrm{~kg} / \mathrm{m}^{2}$, telesne masti: $28 \%$ (35,30 kg), obim struka: $119 \mathrm{~cm}$. U biohemijskim analizama krvi bez zapaljenskog sindroma (SE - 10, 
CRP - 0,5), urednih vrednosti glikemije (glik - 4.75 mmol/1, HbAlc: 5,5\%), urednog lipidnog profila uz značajno sniženje indeksa ateroskleroze $\mathrm{u}$ odnosu na prijem: holesterol - $4.82 \mathrm{mmol} / 1$ (HDL - $1.32 \mathrm{mmol} / \mathrm{l}, \mathrm{LDL}-2,9 \mathrm{mmol} / \mathrm{l})$, trigliceridi - 0,99 $\mathrm{mmol} / \mathrm{l}$. Registrovano značajno sniženje urata u serumu:mokr.kiselina - 532 mikro$\mathrm{mol} / \mathrm{l}$ (norm. manje od $430 \mathrm{mikromol} / \mathrm{L})$, kao i uredne vrednosti elektrolita $(\mathrm{Na}-141$ $\mathrm{mmol} / \mathrm{l}, \mathrm{K}-4.4 \mathrm{mmol} / \mathrm{l}, \mathrm{Cl}-109 \mathrm{mmol} / \mathrm{l}, \mathrm{Ca}-2.47 \mathrm{mmol} / \mathrm{l})$. Ostali biohemijski parametri u referentnim vrednostima. Vrednosti krvnog pritiska i slika EKG-a u referentnim vrednostima (TA: 124/76 mm Hg, Fr: 72/min, EKG: sin. ritam, bez ST-T promena). Pacijent je dobio preporuku za dalji gubitak težine, fizičkog treninga i dijetetskog režima ishrane u kućnim uslovima, kontrolu krvnog pritiska i biohemijskih parametara krvi.

Nakon dve godine od započinjanja tretmana pacijent je ponovo došao na Čigota program - zakazana kontrolna merenja. Antropometrijska merenja na kontrolnom pregledu - TV: $189 \mathrm{~cm}$, TM: 107,8 kg, BMI: $29.86 \mathrm{~kg} / \mathrm{m} 2$, telesne masti: $12.80 \%$ $(13,8 \mathrm{~kg})$, obim struka: $105 \mathrm{~cm}$. Biohemijske analize krvi u referentnim vrednostima: glik - $5.2 \mathrm{mmol} / \mathrm{l}, \mathrm{HbA} 1 \mathrm{c}: 5,3 \%$, holesterol - $4.35 \mathrm{mmol} / \mathrm{l}$ (HDL - $1.4 \mathrm{mmol} / \mathrm{l}$, LDL $-2,5 \mathrm{mmol} / \mathrm{l}$ ), trigliceridi - 1,28 mmol/1, mokr. kiselina - $330 \mathrm{mikromol} / \mathrm{l}$ (normalno manjeod 430 mikromol/L). Vrednosti elektrolita u serumu u normalnom opsegu: $\mathrm{Na}$ - $140 \mathrm{mmol} / \mathrm{l}, \mathrm{K}-4.6 \mathrm{mmol} / \mathrm{l}, \mathrm{Cl}-109 \mathrm{mmol} / \mathrm{l}, \mathrm{Ca}-2.41 \mathrm{mmol} / \mathrm{l}$. Azotne materije u krvi , transaminaze i bilirubini u referentnim vrednostima. Vrednosti krvnog pritiska u normalnom opsegu, kao i nalaz EKG-a,a na ultrazvuku srca: debljina septuma - 9.5mm, uredne dimenzije leve komore (55/37 mm) i EF:65\%, uz nepromenjene dimenzije leve pretkomore ( $41 \mathrm{~mm}$ ) i desne komore (u odnosu na prvi pregled), a bez raslojavanja u perikardu.

Data je preporuka za dalje kontrole i nastavak sprovođenja održavanja zdravog načina života, pravilne ishrane i redovne fizičke aktivnosti.

\section{Diskusija}

Postoji pozitivna (linearna) korelacija između prekomerne težine i gojaznosti i krvnog pritiska. $(4,5)$

Procena na osnovu metaanaliza prospektivnih studija je da je za svaki $1 \mathrm{~cm}$ povećanja obima struka za 2\% je povećan rizik za kardiovaskularne događaje. $(2,6)$

Metabolički sindrom je naziv za skup kardiometaboličkih faktora rizika koji se javlja kao posledica insulinske rezistencije i abnormalnog nakupljanja i funkcije masnog tkiva. (7) Za dijagnozu metaboličkog sindroma potrebno je utvrditi najmanje tri metabolička rizična faktora od sledećih:

1. abdominalni tip gojaznosti (obim struka $\geq 94 \mathrm{~cm}$ muškarci, a žene $\geq 80 \mathrm{~cm}$, BMI $>30 \mathrm{~kg} / \mathrm{m}^{2}$ ) - ako je BMI $>30 \mathrm{~kg} / \mathrm{m}^{2}$, nije potreban obim struka;

2. glukoza na tašte $\geq 5.6 \mathrm{mmol} / \mathrm{L}$ ili uzimanje lekova za hiperglikemiju; 
3. trigliceridi $\geq 1.7 \mathrm{mmol} / \mathrm{L}$ ili uzimanja lekova za hipertrigliceridemiju;

4. HDL holesterol $<1.03 \mathrm{mmol} / \mathrm{L}$ (muškarci) ili $<1.29 \mathrm{mmol} / \mathrm{L}$ (žene) ili uzimanje lekova za sniženi HDL;

5. vrednosti krvnog pritiska $\geq 130 / 85 \mathrm{~mm}$ Hg ili uzimanje lekova za hipertenziju. (8)

Primarni cilj u tretmanu pacijenata sa viškom telesne težine i metaboličkim sindromom je redukcija telesne težine. Redukcijom težine za 5-10\% postižu se značajni efekti na kardiovaskularne faktore rizika (uglavnom na dislipidemije i hipertenziju), kontrolu glikemije, insulinsku rezistenciju, učestalost dijabetesa i kvalitet života. $(3,9)$

Sa povećanjem telesne težine dolazi do povećanja ekstracelularnog i minutnog volumena, što je udruženo sa povećanom metaboličkom aktivnošću u tkivima i povećanom potrošnjom kiseonika. To dovodi do razvoja inflamacije i oksidativnog stresa u tkivima, aktivacije multiplih neurohumoralnih sistema (od kojih RAAS sistem ima ključnu ulogu), što doprinosi razvoju endotelne disfunkcije i oštećene vazodilatacije (povećan "arterial stiffening"). Gojaznost generalno dovodi do povećanja simpatičke aktivnosti koja je udružena sa povećanom srčanom frekvencom i posledičnom RAAS aktivacijom. (11)

Povećana koncentracija leptina kod gojaznih je u pozitivnoj korelaciji sa povećanjem simpatičke aktivnosti. (12)

Framingamska studija je pokazala da je oko dva puta veća prevalenca hipertenzije kod gojaznih u odnosu na normalno uhranjene osobe pripadnike oba pola: u okviru studije pokazano je da $78 \%$ muškaraca i $65 \%$ žena sa prekomernom težinom imaju hipertenziju. Za svaka $4,5 \mathrm{~kg}$ povećanja telesne težine došlo je do povećanja sistolnog pritiska za $4 \mathrm{~mm} \mathrm{Hg}$. Redukcija za 5,5 $\mathrm{mm} \mathrm{Hg}$ sistolnog, a $3 \mathrm{~mm} \mathrm{Hg}$ dijastolnog pritiska, smanjuje za $15 \%$ incidencu koronarne bolesti i za $27 \%$ incidence šloga. (13)

Potencijalno mogući biološki mehanizmi koji povezuju gubitak telesne težine i telesnih masti i posledično smanjenje kardiovaskularnog rizika su popravljanje endotelne disfunkcije, smanjenje insulinske rezistencije, izmene u metabolizmu natrijuma i promene $u$ transportu jona, izmene u stimulaciji RAAS-a i simpatičkog nervnog sistema, izmene vaskularne strukture i funkcije (smanjenje vaskularne rezistencije "arterial stiffening"), promene koncentracija natriuretskih peptida. $(3,9)$

U zapadnim zemljama prosečan dnevni unos soli je visok (9 do $10 \mathrm{~g}$ na dan), dok je preporučeni maksimum do $5 \mathrm{~g}$ dnevno. Čak i mala redukcija unosa soli (1g na dan) redukuje sistolni krvni pritisak za 3,1 mm Hg u hipertenzivnih pacijenata, a 1,6 $\mathrm{mm} \mathrm{Hg} \mathrm{u} \mathrm{normotenzivnih} \mathrm{pacijenata.} \mathrm{Povećani} \mathrm{unos} \mathrm{kalijuma} \mathrm{(putem} \mathrm{voća} \mathrm{i} \mathrm{povrća)}$ ima pozitivne efekte na krvni pritisak i smanjenje rizika od pojave šloga. (14)

Svakodnevna umerena fizička aktivnost prosečno smanjuje za $11 \mathrm{~mm} \mathrm{Hg}$ sistolni, a za $8 \mathrm{~mm} \mathrm{Hg}$ dijastolni krvni pritisak. Fizička aktivnost smanjuje krvni pritisak približno kod $75 \%$ osoba sa hipertenzijom. Mnoge studije do sada su pokazale da 
redovna, individualno dozirana, fizička aktivnost može da poboljša biološku efikasnost insulina. Važno je istaći da ta aktivnost mora biti aerobnog karaktera. (15)

Fizička aktivnost potencira dejstvo insulina na periferna tkiva (skeletni mišići), povećava klirens glukoze u jetri i smanjuje joj produkciju. Povećava se odgovor GLUT-4 i enzima koji regulišu deponovanje i oksidaciju glukoze u skeletnim mišićima. $(15,16)$ Smanjuju se abdominalni depoi masti i intramuskularni depoi triglicerida. Uvećanje mišićne mase povećava prostor za deponovanje glikoze, čime doprinosi smanjenju insulinske rezistencije. Jetra postaje osetljivija na insulin i bolje kontroliše produkciju glikoze. Poboljšava se kontrola metabolizma slobodnih masnih kiselina, povećava se periferni klirens glikoze, a takođe i smanjuje produkcija glikoze u jetri. (17)

Nefarmakološke mere je poželjno primeniti istovremeno, jer dijeta aktivira tirozin-kinazu insulinskog receptora i snižava plazmatske koncentracije glikoze i insulina, a fizička aktivnost ne samo da smanjuje koncentraciju u plazmi glikoze, insulina i slobodnih masnih kiselina, već i povećava gustinu kapilara u skeletnim mišićima. Dijeta i fizička aktivnost čine da mišićne ćelije i druga ciljna tkiva bolje reaguju na insulin, te i bolje koriste glukozu. (18)

Tokom dugotrajnijeg tretmana gojaznosti, uz hipokalorijsku ishranu, nizak dnevni unos natrijuma i redovno sprovođenje aerobnog i anaerobnog vežbanja, potrebna je i adekvatna hidracija. Neretko se registruju elektrolitni i metabolički poremećaji koji se češće javljaju kod tretmana gojaznosti van medicinskog nadzora, kod starijih osoba, kod osoba koje se već leče od drugih oboljenja (komorbiditeti): dijabetes, hipertenzija, metabolička, gastroenterološka oboljenja, psihoza. $(19,20)$

Najčešći elektrolitni poremećaji su: hiponatremija, hipokalijemija, hipomagnezijemija i hipokalcemija, a od metaboličkih hipoglikemija, praćeni blažom ili izraženijom simptomatologijom. Navedene poremećaje je potrebno na vreme prepoznati i korigovati adekvatnom terapijom. (21)

U opisanom prikazu pacijenta koji je bio na terapiji gojaznosti u našoj ustanovi, u okviru Čigota programa, na kraju tretmana (160 dana) postignut je ukupni gubitak telesne mase od $105,8 \mathrm{~kg}$, odnosno za $45,86 \%$ prvobitne težine. Postignuta je značajna redukcija telesnih masti za $68,8 \%$ prvobitnih vrednosti, odnosno gubitak 75,5 $\mathrm{kg}$ telesnih masti; redukcija obima struka za $61 \mathrm{~cm}$, odnosno $33,8 \%$ (od $180 \mathrm{~cm}$ na $119 \mathrm{~cm}$ ). Uspostavljena nefarmakološka regulacija hipertenzije: vrednosti tenzije prosečno oko 120-130/75-82 mm Hg. Uspostavljena regulacija glikemije i triglicerida, uspostavljen povoljan profil frakcija holesterola (HDL/LDL), značajno redukovana vrednost mokraćne kiseline u serumu i time postignuto značajno sniženje kardiovaskularnog rizika i pacijent je ,izašao” iz zone visokog kardiometaboličkog rizika i iz kriterijuma metaboličkog sindroma.

Tokom hospitalizacije u okviru tretmana gojaznosti došlo je do razvoja elektrolitnog disbalansa koji je anamnestički i uz komorbiditet (psihoza) protumačen kao 
diluciona hiponatremija sa hipokalijemijom. Navedeni disbalans elektrolita bio je umerene simptomatologije $\mathrm{i}$ hroničnog razvoja i korigovan je tokom narednih sedam dana adekvatnom peroralnom suplementacijom kalijuma, natrijuma, magnezijuma i restrikcijom unosa tečnosti. $(20,21)$

Tokom nastavka boravka nije bilo signifikantnih hemodinamskih, metaboličkih i elektrolitnih poremećaja i bez značajnije kliničke simptomatologije. Došlo je do povlačenja gotovo svih tegoba, osim povremeno nesanice i osećaja napetosti i strahova u sklopu osnovnog oboljenja (psihoze).

Nakon otpusta iz naše ustanove i dobijenih uputstava i preporuka za nastavak sprovođenja dijetetskog režima i fizičkog treninga u kućnim uslovima pacijent je nastavio trend gubitka telesne težine. Sve vreme je bio u kontaktu sa našim Čigota timom (lekar, nutricionista, profesor sporta, psiholog) i obavljao redovne medicinske kontrole u mestu boravka, kako je savetovano.

Nakon godinu i po dana od otpusta iz naše ustanove pacijent je došao na Čigota program na zakazana kontrolna merenja i medicinske preglede. I nakon dve godine od započinjanja tretmana gojaznosti u našoj ustanovi pacijent je u kućnim uslovima nastavio trend gubitka težine (redukcija $18,1 \mathrm{~kg}$, odnosno za $14.3 \%$ u proteklom periodu), uz dalju značajnu redukciju telesnih masti (za $15,2 \%$, odnosno $21,5 \mathrm{~kg}$ ) i obima struka (za $14 \mathrm{~cm}$, odnosno za 11,8\%). Pacijent je postigao prelazak iz kategorije gojazan u kategoriju prekomerno uhranjen. Uspostavljena je stabilna regulacija krvnog pritiska, popravljeni metabolički parametri kardiovaskularnog rizika (glikemija, holesterol sa frakcijama, trigliceridi, mokraćna kiselina), a u nalazu ultrazvuka srca došlo je do redukcije debljine septuma i popravljanja ejekcione frakcije srca. Time je uspostavljena značajna redukcija ukupnih kardiometaboličkih faktora rizika, što je i krajnji cilj terapije gojaznosti u okviru Čigota programa.

\section{Reference}

1. Zhang C., Rexrode K.M., van Dam R.M., Li T.Y., Hu F.B. Abdominal obesity and the risk of all-cause, cardiovascular, and cancer mortality: sixteen years of follow-up in US women. Circulation 2008,117: 1658-1667.

2. Carl J. Lavie, Richard V. Milani, Hector O. Ventura.Obesity and Cardiovascular Disease. JACC,May 2009, 53 (21):1925-1932.

3. Schneider R, Golzman B, Turkot S et al . Effect of weight loss on blood pressure, arterial compliance, and insulin resistance in normotensive obese subjects. Am J Med Sci 2005, 330: $157-160$.

4. Jiang SZ, Lu W, Zong XF, Ruan HY, Liu Y. Obesity and hypertension. Exp Ther Med. 2016; 12(4): 2395-2399.

5. Chandra A, Neeland IJ, Berry JD et al. The relationship of body mass and fat distribution with incident hypertension: observations from the Dallas Heart Study. J Am Coll Cardiol 2014; 64: 997-1002. 
6. See R., Abdullah S.M., McGuire D.K., et al. The association of differing measures of overweight and obesity with prevalent atherosclerosis: the Dallas Heart Study. J Am Coll Cardiol 2007; 50: 752-759.

7. Eckel R.H., Grundy S.M., Zimmet P.Z. The metabolic syndrome. Lancet 2005; 365: 1415-1428.

8. Mongraw-Chaffin M., Foster C.M, Anderson A.M.C, Burke G et al.Metabolically Healthy Obesity, Transition to Metabolic Syndrome, and Cardiovascular Risk, JACC May 2018; 71 (17): 1857-1865.

9. Straznicky NE, Grima MT, Eikelis N, Nestel PJ et al.The effects of weight loss versus weight loss maintenance on sympathetic nervous system activity and metabolic syndrome components.J Clin Endocrinol Metab. 2011; 96: E503-E508.

10. Straznicky NE, Grima MT, Eikelis N, Nestel PJ et al. The effects of weight loss versus weight loss maintenance on sympathetic nervous system activity and metabolic syndrome components.J Clin Endocrinol Metab. 2011; 96: E503-E508.

11. Lambert EA, Straznicky NE, Dixon JB, Lambert GW. Should the sympathetic nervous system be a target to improve cardiometabolic risk in obesity?Am J Physiol Heart Circ Physiol. 2015; 309: H244-H258.

12. Hall JE, da Silva AA, do Carmo JM, Dubinion J et al. Obesity-induced hypertension: role of sympathetic nervous system, leptin, and melanocortins.J Biol Chem. 2010; 285: 17271-17276.

13. Wilson PW, D'Agostino RB, Sullivan L, Parise H et al.Overweight and obesity as determinants of cardiovascular risk: the Framingham experience.Arch Intern Med. 2002; 162: 1867-1872.

14. Blumenthal A.J,Sherwood A, Smith JP, Hinderliter A.The Role of Salt Reduction in the Management of Hypertension.JACC. April 2018; 71 (14): 1597-1598.

15. Swift DL, Johannsen NM, Lavie CJ, Earnest CP, Blair SN, Church TS. Effects of clinically significant weight loss with exercise training on insulin resistance and cardiometabolic adaptations. Obesity. 2016; 24(4): 812-819.

16. Swift DL, Johannsen NM, Lavie CJ, Earnest CP, Church TS. The Role of Exercise and Physical Activity in Weight Loss and Maintenance. Prog Cardiovasc Dis. 2014; 56(4): 441-447.

17. Kraus WE, Houmard JA, Duscha BD, Knetzger KJ, Wharton MB, McCartney JS, et al. Effects of the Amount and Intensity of Exercise on Plasma Lipoproteins. N Engl J Med. 2002; 347(19): 1483-1492.

18. Wu T, Gao X, Chen M, van Dam RM . Long-term effectiveness of diet-plus-exercise interventions vs. diet-only interventions for weight loss: a meta-analysis. Obes Rev 2009; 10: 313-323.

19. Sterns RH, Silver SM. Complications and management of hyponatremia. Curr Opin Nephrol Hypertens. 2016; 25:114-119.

20. Lien Y-HH, Shapiro JI. Hyponatremia: clinical diagnosis and management. Am J Med. 2007;120:653-658.

21. Sterns RH. Disorders of plasma sodium-causes, consequences, and correction. N Engl J Med. 2015; 372: 55-65. 